\title{
Study on the Professional Growth Management Mode of Clinical Nursing Teachers
}

\author{
Wei Hongjuan ${ }^{1}$, Yang Liqun ${ }^{1}$, Ma Xiumei ${ }^{2}$ \\ ${ }^{1}$ Qiqihar Medical University, Qiqihar, Heilongjiang, 161006 \\ ${ }^{2}$ Second Affiliated Hospital of Qiqihar Medical University, Qiqihar, Heilongjiang, 161006
}

Keywords: clinical nursing teacher; professional growth; management mode

\begin{abstract}
To understand the existence, difficulties, problems and development trends of clinical teacher teaching, and to explore the strategies and applications of clinical nursing teachers' professional growth and management, through literature research, questionnaires, in-depth interviews and other methods are applied to conduct, collect and analyze relevant data in a planned and systematic manner. Through the investigation of the teaching ability of clinical nursing teachers by experts and students, the problems in the professional growth of clinical nursing teachers are found. A comprehensive model for the professional development and training management of clinical nursing teachers is established to seek ways and methods to improve the quality and level of clinical nursing teachers.
\end{abstract}

\section{Introduction}

The clinical nursing teacher is a certain entrustment to the society. According to the syllabus, the nursing staff who exert a specific influence on the students' physical and mental during the clinical learning process is to teach the cognitive of the nursing students through model demonstrations and teaching activities during the clinical learning process, emotional and clinical skills, and care professionals who promote the development of student professional behavior [1]. The knowledge, ability, motivation of clinical nursing teachers, and the education and teaching activities and atmosphere they organize are important basic conditions for achieving clinical teaching goals. Therefore, the professional level and ability of clinical nursing teachers are very important [2]. The aim of this study is to improve the clinical nursing teachers' professional knowledge and teaching level, and to take the opportunity of the comprehensive model of clinical nursing teachers' professional growth and training management to conduct a new comprehensive mode of intervention to improve the clinical nursing teaching quality.

\section{1. Research Objects and Methods}

\subsection{Study Object}

From September 2016 to September 2017, 30 clinical nursing teachers from the three affiliated hospitals of Qiqihar Medical College who have worked for more than 5 years and have intermediate or above professional titles were selected as the study subjects, all of whom were females with an average age of $38.62 \pm 4.35$ years; 8 postgraduates, 15 undergraduates, 7 postgraduates, 11 titles, 11 senior titles, 19 intermediate titles, 26 years of work in 5-10 years, 4 years of 10 years, and 10 years of teaching experience. The above 6 people, 14 people 5-9 years, 10 people less than 5 years.

\subsection{Methods}

\subsubsection{Field survey}

After consulting a large amount of literature, the questionnaire was initially designed to comprehensively use various survey methods and methods to collect and analyze related data in a planned and systematic manner to find problems in the professional growth of clinical nursing teachers and to provide professional growth for clinical nursing teachers. The study provides 
sufficient factual evidence. Through a questionnaire survey conducted by 113 nursing students of 2015 and 2016 levels, an overall assessment of the clinical nursing teacher's teaching process was conducted to further understand clinical nursing teachers' problems in the teaching process. Questionnaires were distributed uniformly and recovered on the spot, with a questionnaire recovery rate of $100 \%$, valid questionnaires of 102 , and an effective rate of $90.27 \%$.

\subsubsection{In-depth interview}

Qualitative surveys use personal in-depth interviews to design corresponding interview outlines.

\subsubsection{Statistical Methods}

SPSS17.0 software package was used for data processing, and standard deviation and percentage were used for correlation analysis.

\section{Results}

\subsection{Investigation of Classroom Teaching Ability of Clinical Nursing Teachers}

To investigate the teaching objectives, teaching contents, teaching methods, basic teaching skills, and teaching effects of clinical nursing teachers, and to evaluate the teaching quality of clinical nursing teachers so that clinical nursing teachers can obtain comprehensive and comprehensive feedback information and improve nursing teaching in a timely manner. Methods to improve nursing teaching quality. Through the real-time monitoring of the quality of nursing education, it provides decision-making basis for nursing teaching management and nursing teaching reform, as shown in Table 1.

Table 1 Evaluation of classroom teaching ability of clinical nursing teachers (person/percentage)

\begin{tabular}{ccccc}
\hline Item Name & $\begin{array}{c}\text { Fully up to standard } \\
\text { (Excellent) }\end{array}$ & $\begin{array}{c}\text { Basically } \\
\text { achieved } \\
\text { (good) }\end{array}$ & $\begin{array}{c}\text { Most achieved } \\
\text { (middle) }\end{array}$ & $\begin{array}{c}\text { Majority did not reach } \\
\text { (difference) }\end{array}$ \\
\hline $\begin{array}{c}\text { Teaching } \\
\text { objectives } \\
\text { Teaching }\end{array}$ & $3(11.11)$ & $17(62.96)$ & $4(14.81)$ & $3(11.11)$ \\
$\begin{array}{c}\text { Content } \\
\text { Teaching }\end{array}$ & $8(29.92)$ & $16(59.25)$ & $3(11.11)$ & $0(0)$ \\
$\begin{array}{c}\text { Methods } \\
\text { Teaching }\end{array}$ & $5(18.51)$ & $16(59.25)$ & $5(18.51)$ & $1(3.70)$ \\
$\begin{array}{c}\text { Basic Skills } \\
\text { Teaching } \\
\text { Effect }\end{array}$ & $9(33.33)$ & $13(48.14)$ & $3(11.11)$ & $2(7.40)$ \\
\hline
\end{tabular}

\subsection{Evaluation of clinical nursing teachers' teaching ability}

Investigated 102 students of 2015 and 2016 nursing majors, investigated the teaching contents and teaching methods of clinical nursing teachers, and conducted a systematic and comprehensive search of relevant teaching information to provide scientific analysis and processing of collected information. The process of measuring and measuring the whole process of teaching activities of clinical nursing teachers and their results, and the process of making value judgments and assessments are shown in Table 2. 
Table 2 Student's Evaluation of Teaching Ability to Clinical Nursing Teachers

\begin{tabular}{|c|l|c|c|}
\hline No. & \multicolumn{1}{|c|}{ Evaluation Indicators } & Number & $\begin{array}{c}\text { Percentage } \\
\text { (\%) }\end{array}$ \\
\hline 1 & Instrumentation, good demeanor, serious teaching attitude & 62 & 60.78 \\
\hline 2 & Smooth, lively, full of passion & 68 & 66.67 \\
\hline 3 & $\begin{array}{l}\text { Attention to guide, mobilize students' thinking and } \\
\text { motivation for learning }\end{array}$ & 61 & 59.80 \\
\hline 4 & $\begin{array}{l}\text { The theory can be linked to reality, and the amount of } \\
\text { information in the classroom is large }\end{array}$ & 59 & 57.84 \\
\hline 5 & $\begin{array}{l}\text { Neat board, reasonable layout, clear writing } \\
\text { time }\end{array}$ & 67 & 65.68 \\
\hline 7 & $\begin{array}{l}\text { Rigorous scholarship, strict requirements on student learning } \\
\text { discipline }\end{array}$ & 71 & 63.72 \\
\hline 8 & $\begin{array}{l}\text { Can answer questions carefully and patiently } \\
\text { Respect and care for students, teacher-student relationship is } \\
\text { harmonious }\end{array}$ & 70 & 71.56 \\
\hline
\end{tabular}

\section{Discussion}

\subsection{The problems of clinical nursing teachers in teaching}

\subsubsection{Role-playing conflicts, lack of specificity in teaching}

Clinical nursing teachers play multiple roles. In addition to teachers and nurses in clinical practice, the work content is very complex and the workload is large. Different roles have significant contradictions and differences in terms of content and degree [3]. The role of a part of clinical nursing staff as a clinical nursing teacher is not their own intention and cannot be devoted to teaching.

\subsubsection{Insufficient teaching experience and poor teaching ability}

Some clinical nursing teachers are affected by traditional education thoughts and teaching models. Classes are taught according to the text, lack of interaction, and teaching methods are old-fashioned. They are unable to guide students' ability to study independently. They do not know or can not integrate into new teaching methods. What is more, it lacks the ability of combining theory with practice, cannot combine its own work experience with theory, and cannot keep up with the development of medicine and education, lack of updating of educational concepts, and the application and reform of teaching methods.

\subsubsection{Insufficient awareness of innovation and unreasonable knowledge structure}

In the teaching process, the teaching content is not comprehensive enough and the knowledge structure is not reasonable enough. The teaching consciousness is not strong, and the theory and practice cannot be more flexible [4]. There are also some clinical nursing teachers with outdated knowledge that cannot be updated in time and lack a certain degree of innovation.

\subsubsection{Insufficient professionalism and low teaching mood}

The lack of enthusiasm in teaching and the lack of professionalism have made it difficult to improve the quality of nursing education. In medical colleges, there are clinical nursing teachers and clinical and teaching duties. Their job burnout has become a problem that cannot be ignored [5]. The lack of professionalism and job burnout of clinical nursing teachers is related to their social environment, work environment, occupational specificity, and individual factors. 


\subsubsection{The low quality of care, and less focuses on medical care from hospitals}

The status of nursing education is often not guaranteed, and the quality and effectiveness of teaching are not valued enough. As a result, the quality of nursing care is not high. Therefore, attention is not paid to nursing education, which results in inferior quality of nursing education. Driven by policies, nursing staff lacked attention to quality of care and nursing education and formed a bad cycle.

\subsection{Clinical nursing teacher professional growth management model}

\subsubsection{Selection of clinical nursing teachers}

(1) The selection criteria: love teaching work [6], has a good professional nursing attitude, has a high degree of responsibility for the work, love of patients and students, students can be strictly managed, with certain teaching methods and measures.

(2) An undergraduate degree or above graduate with a master degree in nursing, who has extensive knowledge of nursing theory, and has rich clinical experience and skilled professional skills.

(3) Being good at learning and summarizing in nursing education, innovating teaching methods and putting forward constructive opinions and suggestions.

\subsubsection{Year-end quantitative assessment system for clinical nursing teachers}

Each year, clinical nursing teachers conduct a comprehensive assessment of the theory and skills, and regularly solicit the opinions and suggestions of students, nursing school teachers, and nurse head nurses. The overall evaluation of clinical nursing teachers, selected outstanding clinical teaching teachers of the year [7]. The evaluation and evaluation items include: knowledge and operation assessment, evaluation of teaching activities, implementation of teaching plans, student questionnaires for teachers, questionnaires for teachers of nursing schools for clinical teachers, questionnaires for department nurses on clinical teachers, and publications the situation of the paper and so on. Motivate the majority of teachers to actively participate in the first line of teaching, teaching first, proud of teaching, and enthusiastic about teaching reform. The whole process of clinical nursing teachers' teaching activities and their results are measured and measured, and the process of value judgment and evaluation is made [8].

\subsubsection{Strengthen the training of clinical nursing teachers}

Various types of training courses for clinical nursing teachers were set up, training for clinical nursing teachers was organized, and training courses at different levels and in different forms were often held [9]. Encourage and arrange clinical nursing teachers to participate in various forms of lectures and reports, employ experts with extensive experience to conduct series of special lectures, conduct regular formal training for clinical nursing teachers, and improve the comprehensive professional qualities of nursing teachers.

\section{Conclusion}

Nursing teaching is a medical education that integrates theory, practice and skills. It has become a most urgent need for nursing education by building a stable, dedicated and integrated team of clinical nursing teachers through selection, assessment, and training. Clinical nursing teachers can make nursing students change their professional roles as quickly as possible by explaining clinical common and typical cases, and gain professional knowledge and professional skills. Nursing major is an applied subject with strong practicality. The quality and quality of clinical nursing teachers influence the quality of teaching to a certain extent, and it is particularly important to strengthen the management of clinical nursing teachers. 


\section{Acknowledgement}

This article is the result of the project Heilongjiang Provincial Department of Education Humanities and Social Science Project, project ID: 12542335.

\section{References}

[1] Li Xiaomei. Nursing education [M]. Beijing: People's Medical Publishing House, 2002, 30-35.

[2] Song Yanli, Tian Mingming, Liang Yujie. Factors affecting the convergence of nursing education and clinical practice Nursing strategy [J]. Chinese School Education, 2015(7).10-12.

[3] Zhu Lingyan, Xu Yanling. Investigation on status and influencing factors of clinical nursing teachers' work pressure Analysis [J]. Modern Clinical Nursing, 2017, 16(3). 41-44.

[4] Yang Daofeng. Problems and countermeasures in nursing clinical teaching in the new era [J]. Modern Medicine Health, 2013, 29(4).616-619.

[5] Zeng Jiayuan, Chen Yu, Gan Min. Survey and scores of occupational benefit of clinical nursing teachers Analysis [J]. Chinese Journal of Practical Nursing, 2013, 29(32).57-60.

[6] Deng Jiaxiu, Ying Yanping. Recognition of evidence-based nursing knowledge by clinical nursing teachers and undergraduate nursing students. Investigation of Knowledge[J]. Journal of Nursing Science,2010,25(4).75-77.

[7] Dong Rui, Xu Hong, Lou Zhen, Yan Huimin. Clinical Practice of Nursing Specialty Teachers in China's Undergraduate Colleges Practice status and outlook[J]. Qilu Nursing Journal, 2017, 23(6).59-60.

[8] Xu Weiwei, Wu Jiancheng, Jiang Bijian, Gong Fanghong. Evaluation System of College Teachers' Teaching Quality Research and Practice in China[J]. China Higher Education, 2011, 32(1). 100-103.

[9] Fang Xiuxin. Construction and implementation of standard nursing management model for clinical nursing teachers [J]. Nursing Academic Journal, 2010, 25(15).11-13. 